and was a local director of 'Health Services'. Helmuth is a television producer and writes poetry. $\mathrm{He}$ cries when he describes how, in a clinic at the University, his father shot himself. As a child Helmuth was convinced that his mother wanted to poison him; he cannot now listen to those beautiful folk songs (Klein schönes Land) with which his father sang him to sleep.

Hilde grew up in the camps where her father was a 'supplier'. Her predominant memory, only now surfacing, is that "they used to call me 'camp doll' all the time, the people in the kitchen and the women at the parties". Thomas, the nephew of Reinhard Heydrich, is an actor who performs cabaret songs of the 1920 s and $30 \mathrm{~s}$ in the local theatres. He specializes in the songs of the German-Jewish poets Tucholsky and Mehring; he wants to go on a reading tour of Israel, reading Heine in the original German. The thought that goes through Bar-On's mind is "they'd kill him". But he does not say this to Thomas, and over lunch he finds himself telling Heydrich's nephew about Lurianic cabalism ("within each evil you find a sign for good"). Thomas in turn tells Bar-On of his girlfriend's brother who converted to Judaism and became an orthodox rabbi.

In the Old City of Jerusalem, Bar-On meets this man (now called Menachem), the son of a prominent member of the SS. With beard, gabardine and kipa, he "teaches Jewish theology and philosophy to Israeli students" at Tel Aviv University. Returning briefly to Germany for his father's funeral, he can feel nothing.

In the concluding chapter, Bar-On suspects he should "analyze his data", but realizes that the point is rather to confront it. Perhaps the third and fourth generations will see more clearly than we do. Or will Bar-On's children be putting similar questions to the children of Ariel Sharon and Meir Kahane? Nearer to home, the right honourable Mr Norman Tebbitt tells us that the criterion for the assimilation of the terrified British residents of Hong Kong into the country whose passports they hold is "which side do they cheer for?". As a British subject with a white skin, albeit, as we used to say, of the "Mosaic persuasion", I had not realized that my continued citizenship of the United Kingdom was dependent upon my active support of the English cricket team (nor that Peking had a cricket team).

Jewish doctrine teaches a counterpart to the 'merit of the fathers' (conspicuously lacking in the fathers described by Dan Bar-On). It is the notion that the righteousness of the living child favourably affects the fate of the dead father. Some of us may need this "merit of the children".

John C. Marshall is in the Neuropsychology Unit, part of the Neuroscience Group at the Radcliffe Infirmary, Oxford OX2 6HE, UK.

\section{Slipping from the heights}

\author{
David J. Prior
}

Mountain Environments. By A. J. Gerrard. Belhaven: 1990. Pp.317. £30.

THERE are few subjects within Earth studies with greater potential for an illuminating and exciting discussion of the interaction of competing geological, geomorphological, biological and human processes than mountain environments. A. J. Gerrard makes a bold attempt to summarize the current understanding of the processes influencing the environmental patterns in the Earth's mountains. The range of source material used is impressive and the bibliography is an invaluable data bank, but I feel the author could have discarded much of the outdated work and attempted to reconcile various approaches and models, even if this had meant imprinting some of his own bias.

Gerrard is preoccupied with semantics and, after reading his book, one has to question the validity and usefulness of simple categorization of complex natural phenomena. Much of Gerrard's discussion revolves around the intricacies of nomenclature: this approach is taken to an extreme in a discussion of the definition of mountains in the early part of the book. When does a hill become a mountain and a mountain a 'high mountain'? Such a distinction is subjective and any discussion thereof is as intractable as it is pointless. Gerard also subjects processes to discriminatory nomenclature. Does it matter whether a landslide event is classified as a rockfall, a rockslide, a debris slide or a debris flow? Of course there are compet-

\section{New Journals}

This year Nature's annual new journals review supplement will appear in the issue of 11 October. Publishers and learned societies are invited to submit journals for review, taking note of the following criteria:

- Journals which first appeared after June 1988 , and which issued at least four separate numbers by the end of April 1990, will be considered for review. The deadline for submission is the end of June.

- Journals covering any aspect of science are eligible, although those dealing with clinical medicine, engineering and pure mathematics are excluded, as are publications of abstracts. - Frequency of publication must be at least three times a year.

- The main language used must be English. Translation journals in English are eligible.

When submitting journals for review, please send at least four different issues (the first, the most recent and any two others) of each title as soon as possible to: Book Review Editor, Nature, 4 Little Essex Street, London WC2R 3LF, UK or 1137 National Press Building. Washington DC 20045, USA. ing processes which contribute to the character of a landslide, but what they are called is largely irrelevant. The study of mountains is predominantly an observational science, and a plethora of processes contribute to mountain environments. The construction of any rigid classification of such complex phenomena limits our ability to analyse them objectively as preconception is often inadvertently built into the classification scheme. A better grasp of mountain environments and their controlling processes will be achieved only by detailed quantitative analysis of the interactions of processes in specific natural examples.

Gerrard clearly appreciates the interdisciplinary nature of his topic, and covers diverse aspects of Earth sciences, biology and social sciences. The natural examples essential for the data source of a review of mountain environments are scattered liberally through the text with little underlying context, and local geographical names are freely used without map reference. The introductory and concluding chapters are vague, verbose and poorly argued. Chapters describing the surface processes which influence mountain morphology comprise the most coherent section of the book. Each of these review chapters is illustrated with excellent synoptic diagrams and tables extracted from the scientific literature. In a chapter on mountain geoecology, Gerrard presents a useful set of data, again mostly in diagrams, but the text is little more than a series of mundane lists that merely duplicates the information in the figures. A chapter on volcanoes as mountains is inappropriate without coverage of the geological controls on non-volcanic mountains in equivalent detail.

A discussion of the potential tectonic controls on mountain development, for which there is now a considerable literature base, is crucial to any treatise on mountain environments, and it is sad that this aspect is ignored in this book. As a geologist, I am alarmed by the misconception of many principles of mechanical behaviour of Earth materials shown by the author and this points to the main failing of this book: the topic of mountain environments is too broad to be covered by one author. The interdisciplinary nature of the subject necessitates that any comprehensive review must consist of a volume of papers written by specialists.

David J. Prior is in the Department of Earth Sciences, Liverpool University, Liverpool L69 3BX, UK.

- Still in the hills, The Magnificent Mountain Women by Janet Robertson, charts the multifarious exploits of women who have ventured into the Colorado Rockies from the 1850 s to the present day. Published by University of Nebraska Press $\$ 28.25$. To be published in Britain 30 June, $£ 20.85$ 